\section{Commentary: The Everest of pediatric cardiac surgery: Unifocalization of aortopulmonary collateral arteries}

\section{Osman O. Al-Radi, FRCSC}

In a recent article about climbing Mount Everest, Huey and colleagues $^{1}$ noted that the success rate has improved over time from $<20 \%$ in the 1970 s to about $70 \%$ in the current decade. The rate of death, which most of time occurs during the descent phase of the climb, has remained low at $1 \%$. There is no question that climbing Mount Everest is not everyone's cup of tea. The drive, dedication, training, and innate and acquired endurance required for the climb are rare among mortals. Huey and colleagues ${ }^{1}$ show that even such tasks are reproducible and can improve over time and with more people doing them. If an operation in pediatric cardiac surgery could be compared with climbing Mount Everest, unifocalization of major aortopulmonary collateral arteries would be it.

As reported in previous publications ${ }^{2}$ and by Mainwaring and colleagues, ${ }^{3}$ single-stage unifocalization can require cardiopulmonary bypass times averaging 6 hours and extending up to 10 or more hours. The operative times would surely be a few hours longer than that, especially with the need for intraoperative flow studies and challenging hemostasis. The authors show that not only is that achievable in hundreds of patients, but also that it produces excellent short- and long-term outcomes. ${ }^{3}$ One can only admire the endurance, determination, and resolve of the surgical team. Surely not every cardiac surgeon's cup of tea.

Climbing Mount Everest might be thought of as a luxury challenge or a fanatical endeavor. If no one did it, little or no

\footnotetext{
From the Faculty of Medicine, Department of Surgery, King Abdulaziz University, Jeddah, Saudi Arabia.

Disclosures: The author reported no conflicts of interest.

The Journal policy requires editors and reviewers to disclose conflicts of interest and to decline handling or reviewing manuscripts for which they may have a conflict of interest. The editors and reviewers of this article have no conflicts of interest.

Received for publication Oct 9, 2021; revisions received Oct 9, 2021; accepted for publication Oct 13, 2021; available ahead of print Oct 19, 2021.

Address for reprints: Osman O. Al-Radi, FRCSC, Faculty of Medicine, Department of Surgery, King Abdulaziz University, PO Box 80215, Building 10, Room 1027, Jeddah 21589, Saudi Arabia (E-mail: oradi@kau.edu.sa).

J Thorac Cardiovasc Surg 2022;163:2182

$0022-5223 / \$ 36.00$

Copyright (c) 2021 by The American Association for Thoracic Surgery

https://doi.org/10.1016/j.jtcvs.2021.10.014
}
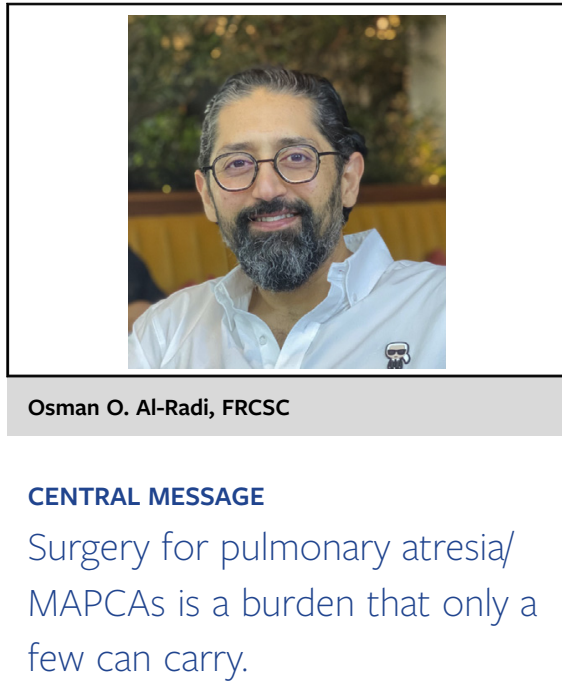

harm will be done. On the other hand, the surgical care of patients with pulmonary atresia/unifocalization of major aortopulmonary collateral arteries is far from that. It is an obligation of the community of congenital cardiac surgery teams in each country or region. If done by some, the rest would be relieved from the burden, but if no one does it, the conscience of all should be bothered.

Who should be the chosen one(s) to take on the challenge? One might think of a socialist deterministic approach and assign a surgeon/group in each area, which in my view is doomed to fail. However, like all other human endeavors, once something is invented or discovered-and if it continues to be needed-the competitive spirit and need to achieve that is at the core of human nature will spur the self-selected few to take the burden off the shoulders of the rest of us. The Mainwaring and colleagues group is living proof of that. The next question is: Who will carry the baton next?

\section{References}

1. Huey RB, Carroll C, Salisbury R, Wang J-L. Mountaineers on Mount Everest: effects of age, sex, experience, and crowding on rates of success and death. PLoS One. 2020;15:e0236919. https://doi.org/10.1371/journal.pone.0236919

2. Margetson TD, Sleasman J, Kollmann S, McCarthy PJ, Jahadi O, Sheff D, et al. Perfusion methods and modifications to the cardiopulmonary bypass circuit for midline unifocalization procedures. J Extra Corpor Technol. 2019;51:147-52.

3. Mainwaring R, Capecci L, Collins T, Hanley F. Midterm fate of unifocalized major aortopulmonary collateral arteries in patients with retroesophageal major aortopulmonary collateral arteries. J Thorac Cardiovasc Surg. 2022;163:2175-81. 